\title{
Architecture Schools and Their Relationship with Research: It's Complicated
}

Jan Silberberger

Editorial Summary: In "Architecture Schools and Their Relationship with Research: It's Complicated «, Jan Silberberger describes the problematic divide between practicing architects that teach design at architecture schools and scholars investigating the practices of designing from a theoretical or social scientific perspective. Identifying three recurrent misunderstandings between these two groups, he stresses the lack of awareness about genuine research approaches within the discipline of architecture. Emphasizing the interconnectivity of research and practice, Silberberger highlights the potential for further development of the discipline that thorough reflections on the methodologies applied in architectural design afford. [Katharina Voigt]

Keywords: Design; Research; Studio Teaching; Theoreticians; Practitioners; Misunderstandings.

»We have taken science for realist painting, imagining that it made an exact copy of the world. The sciences do something else entirely - paintings too, for that matter.« (Bruno Latour 1999: 78-79)

It remains unclear whether Bruno Latour hinted at the work of Paul Feyerabend with this statement. Feyerabend, a philosopher of science, has famously and meticulously elaborated on the parallels between the sciences and the arts, showing that the former are in fact much more creative than many people like to admit - and the latter, in turn, far more rigorous in terms of their methodologies than is commonly supposed (1975; 1984). Most likely, Latour did not. Nevertheless, we may interpret the quote as an indication that corresponding to the distinctively wide variety of painting (in terms of, e.g., objectives, techniques, scale, and audience / market), there is an equally recognizable variety of ways of »doing « science. The notorious contrasting pairs »basic versus applied «, »quantitative versus qualitative«, "government funded versus private« should suffice to prove this point. 
Architecture - as an academic field - seems to echo the ambiguities related to these binary polarities in an almost exemplary manner. At an architecture school, students not only encounter an astounding broadness of thematic fields, methodological approaches, knowledge bases and objectives, but are simultaneously faced with characteristic »ontological« ambivalences:

1. Affected by the economization and new regimentation of higher educational institutions (Braun/Merrien 1999; Schimank 2008), architecture schools developed an increased research orientation during the last ten to fifteen years (Ammon/Froschauer 2013) - more and more so with regard to its core discipline, architectural design (Gethmann/Hauser 2009). While this development is in itself far from problematic (quite the opposite, it should be welcomed), it is bound to become so, if it leads to the somewhat paradoxical target of transferring assessment criteria and procedures from the hard sciences (or the humanities) - without or with only very little scrutinizing to an »epistemic culture (Knorr Cetina 1999) that has hardly any intrinsic or genuine hard science experience (Gisler/Kurath 2015). Such attempts often lead to highly erratic combinations of concepts, functions, perceptions, and effects - which do neither help to practice nor to teach architectural design in a comprehensible, verifiable, non-arbitrary manner.

2. Design architects rarely publish in scientific journals, as the manner in which they are accustomed to presenting their findings is hardly text-based. (It should not be forgotten that the TU Delft has successfully started to tackle this issue by setting up peer-reviewed magazines, such as "SPOOL « or "Writingplace«, which specifically respond to the demands of design architects.) Failing to comply with the expectations and requirements of the established scientific community, most architecture schools nowadays exhibit a characteristically defensive and deficient self-conception. Remarkably though, outsiders often share a completely different perspective of architecture as an academic field. For them, architectural design - and especially the way it is taught - presents itself as a highly advanced field of study. Scholars from management science (Boland/Collopy 2004), for instance, appreciate design for its methodologies that allow for adequately dealing with the uncertainties, ambiguities and non-linearity that govern our complex world. Seen from their point of view, architecture schools constitute sophisticated training grounds for the exploration and manipulation of complex adaptive systems. 


\section{"Practitioners" and "Theoreticians"}

Looking back at the »Research Perspectives in Architecture« conference, one of its most remarkable achievements, to me, was that so-called practitioners - practicing architects that teach design at architecture schools - and so-called theoreticians - scholars investigating the practices of designing, for instance from a social scientific perspective - exchanged their views on the issue of research in architecture in a rather engaging debate. This debate, once more, laid bare the problematic divide between practitioners and theoreticians. Truly remarkable, though, is the fact that it brought the two antagonistic groups together in a way that facilitated the identification of specific sources of conflict and misunderstanding, and indicated, in the end, that their views on architectural design and its methodologies may not be so different.

In particular, the discussions relating to the keynote lecture given by Dietmar Eberle, who runs offices in several countries with more than 250 employees, has taught design at a variety of architecture schools and can be considered an ideal-typical representative of the above-mentioned group of practitioners, pointed to an explicit and significant misunderstanding. Eberle began his talk by pointing out that designers and scientists perform entirely different functions and that therefore, we should simply forget about »research by design«. The longer he spoke, however, the more he conveyed the impression that his work is in fact rather closely related to common definitions of research: for instance, when Eberle presented his publication 9 $99-A$ Method of Design (2018), he argued that the methodology he taught is characterized not only by a high degree of comprehensibility and traceability, but also by its transferability and applicability to a wide range of problems.

Unfortunately, when arguing that a design project or a finished building respectively should be regarded as architecture's true equivalent to a peer-reviewed publication in the hard sciences, Eberle did not go into detail although he could have provided telling examples from his practice. His head office in Lustenau (Austria), for example, perfectly corresponds to the criteria expected for scientific research. It addresses a question - "What is the role for human intervention in an office building that is dispensed with all its heating, ventilation and cooling technology? (see https://www.baumschlager-eberle.com/en/work/projects/projekte-details/2226/). Furthermore, it builds on a clear-cut hypothesis - »Though modern buildings tend to use less 
and less energy, the cost of servicing and maintaining them is growing ever higher (ibid.), and its analysis is presented in a publication (Eberle/Aicher 2015) that is far from the ill-founded architecture coffee-table book.

As a matter of fact, it can be argued that Eberle's $\$ 2226$ « building contributes to all three categories of design research developed by theorists: »research for design«, "research through design«, and »research about design « (Frayling 1993). First, it clearly incorporates knowledge from related fields such as building physics or thermal comfort. Second, we can assume that during the design phase, knowledge (e.g., with regard to the structure of the exterior walls) had been created through »reflection in action« (Schön 1983); moreover, we can state that this practice-based conduct had been combined "with a research question specifically related to research (Schneider 2007: 216) leading to an »applicability of the knowledge gained [that] is not restricted to the product on which research is being conducted « (ibid.). And third, we could argue that the analysis of the building's use constitutes a sociological inquiry about design. In this sense, it does not seem too far-fetched to claim that Eberle, despite condemning the terminology (and the conception), evinces picture-perfect examples of research for, through, and about design in his practice - thereby proving that the topic of the conference as well as the subsequent observations made may in fact not be all that irrelevant for design architects.

\section{Methodology, Scope and Objectives}

The contribution at hand is based on an analysis of data that had been obtained by means of an ethnographic study investigating the teaching of architectural design. Within this study, my colleague, $\mathrm{PhD}$ candidate Kim Helmersen, and I visited selected studios at five architecture schools (ETH Zurich, Technical University of Munich, University of Stuttgart, AA London, KADK Copenhagen), ranging from technical universities to art schools. Although our focus had been on methodologies of designing as they become discernible in studio teaching, we frequently touched upon the issue of »research in architecture«. While our study adopts an approach from Science and Technology Studies (Latour/Woolgar 1979; Knorr Cetina 1981) and primarily aims to provide particular, idiosyncratic and localized accounts (Latour 2005), this contribution constitutes an attempt to form generalizations on the basis of a range of similar observations across our cases. 


\section{Observations and Provocations}

Referring to the sources of confusion addressed in the introduction, in what follows I have compiled three concise descriptions of observations, which I will then combine in a somewhat provocative statement:

a) Most architects (practitioners as well as theoreticians) agree that design methodologies should be non-deterministic and foster a certain degree of freedom - while disagreeing on whether a method should be understood as something rigorous and formalized that possesses precisely defined characteristics or as something supple that can, and has to be, tweaked and adapted to the case at hand.

b) In line with Kurath (Kurath 2015), who argues that knowledge production in architecture can be characterized by a traditional orientation toward ideals such as individuality, singularity and non-reproducibility, the knowledge creation within the studios we observed was related to the development of a particular solution to a (site-)specific task or problem at hand. However, attempts to deduce reproducible, universally applicable answers, insights or theories from this site-specific problem-solving approach were often frowned upon. At the same time, teachers and students drew heavily on references; that is, they searched for projects dealing with a similar problem and/ or comparable conditions and thought about ways of applying them to the task at hand (Silberberger 2021). While this conduct cannot be considered a universalization, it nevertheless clearly represents a form of generalization (Flyvbjerg 2011).

c) Almost everyone working at an architecture school seems to concur with Denise Scott Brown that there is a need for "ways of being rational about uncertainty (Scott Brown 1999: 379). There is, however, a lot of dissent with regard to the degree of traceability, comprehensibility, and verifiability that »these ways « should exhibit. From the perspective of the ethnographer, one cannot help but wonder if those who argue for a small degree, might not just hide behind Cross's famous but also vaguely defined slogan »designerly ways of knowing (Cross 2007), claiming that designers depend on tacit knowledge and rarely produce formal or explicit knowledge. 
It seems safe to say that, despite significant efforts, architecture's core designing - is (still) far from being considered mainstream research, and that the findings it produces rarely function in the sense of marketable products within a global academic system. Hence, it is realistic to anticipate that the economization and harmonization of higher education and the corresponding trend toward an ever-increasing "commodification of academic research" (Nordmann et al. 2011) is likely to impair architectural education. But maybe - and this is the somewhat provocative proposition I would like to make - maybe, the fact that the discipline of architecture is forced to challenge its self-conception, is forced to reflect on its role in relation to other research-based academic disciplines and is forced to think about its (teaching) methodologies is not such a bad thing after all. Maybe it is long overdue.

\section{Conclusion and Outlook}

Perhaps some readers are familiar with the National Endowment of Science, Technology and the Arts (NESTA), an innovation foundation based in the UK. I was not, until I attended a talk by RIBA president Alan Jones in 2019. In this talk, Jones presented an extensive report entitled The Future of Skills: Employment in 2030 issued by NESTA in 2017 (see https://www.nesta.org. $\mathrm{uk} /$ report/the-future-of-skills-employment-in-2030/). As its title already suggests, this report deals with the question of which skills remain or become relevant in the course of the rise of artificial intelligence. For the field of architecture, the report reveals either very bad or relatively good news depending on one's understanding of the discipline.

Out of the 120 skills which NESTA has assessed, designing is ranked 68th in terms of relevance, which suggests that one should think about cutting down on its education. This obviously does not sound too good. Interestingly though, skills such as "Judgment and Decision-making" (ranked 1st), »Fluency of Ideas« (ranked 2nd), »Complex Problem Solving« (ranked 8th) or »Critical Thinking« (ranked 11th) are considered most important. Yet wouldn't we - almost naturally - associate these four skills with designing? Wouldn't we say that these four top-tier skills constitute an integral part of every design process? 
To conclude, I would like to pose three interconnected questions:

- Will the field of architecture be able to understand (and communicate) its core practice - designing - in relation to these future core skills?

- That is, will it be able to produce descriptions of its methodologies that go beyond singular cases without losing density and specificity?

- And will it be able to systemize and frame the complex proceedings undertaken within the design studio as effective processes of knowledge transfer and creation?

References

Ammon, Sabine/Froschauer, Eva Maria, eds. (2013): Wissenschaft Entwerfen: Vom forschenden Entwerfen zur Entwurfsforschung der Architektur, Paderborn: Wilhelm Fink Verlag.

Boland, Jr., Richard J./Collopy, Fred, eds. (2004): Managing as Designing, Stanford, CA: Stanford University Press.

Braun, Dietmar/Merrien, FrançoisXavier, eds. (1999): Toward a New Model of Covernance for Universities? A Comparative View, London: Kingsley.

Cross, Nigel (2007): Designerly Ways of Knowing, Basel: Birkhäuser.

Eberle, Dietmar/Aicher, Florian, eds. (2015): be 2226_Die Temperatur der Architektur/ be 2226_The Temperature of Architecture, Basel: Birkhäuser.

Eberle, Dietmar/Aicher, Florian, eds. (2018). 9x 9-A Method of Design, Basel: Birkhäuser.

Feyerabend, Paul (1975): Against Method, London: New Left Books.
Feyerabend, Paul (1984): Wissenschaft als Kunst, Frankfurt am Main: Suhrkamp.

Flyvbjerg, Bent (2011): »Case Study«, in: Norman K. Denzin/Lincoln, Yvonna S., eds., The Sage Handbook of Qualitative Research, Thousand Oaks, CA: Sage, 301-316.

Frayling, Christopher (1993): »Research in Art and Design «, in: Royal College of Art Research Papers 1, no. 1, London: Royal College of Art, 1-5.

Gethmann, Daniel/Hauser, Susanne (2009): Kulturtechnik Entwerfen. Praktiken, Konzepte und Medien in Architektur und Design Research, Bielefeld: transcript Verlag.

Gisler, Priska/Kurath, Monika (2015): »Architecture, design et arts visuels: les transformations des disciplines après la Réforme de Bologne«, in: Gorga, Adriana/ Leresche, Jean-Philippe, Disciplines académiques en transformation: Entre innovation et résistance, Paris: Editions des Archives Contemporaines, 165-179. 
Knorr Cetina, Karin (1981): The Manufacture of Knowledge: An Essay on the Constructivist and Contextual Nature of Science, Oxford: Pergamon Press.

Knorr Cetina, Karin (1999): Epistemic Cultures: How the Sciences Make Knowledge, Cambridge MA: Harvard University Press.

Kurath, Monika (2015): »Architecture as a Science: Boundary Work and the Demarcation of Design Knowledge from Research «, in: Science \& Technology Studies 28(3), Helsinki: Finnish Association for Science and Technology Studies, 81-100.

Latour, Bruno (2005): Reassembling the Social: An Introduction to Actor-NetworkTheory, Oxford: Oxford University Press.

Latour, Bruno (1999): Pandora's Hope: Essays on the Reality of Science Studies, Cambridge, MA: Harvard University Press.

Latour, Bruno/Woolgar, Steve (1979): Laboratory Life: The Social Construction of Scientific Facts, Princeton: Princeton University Press.

Nordmann, Alfred/Radder, Hans/ Schiemann, Gregor, eds. (2011): Science Transformed? Debating Claims of an Epochal Break, Pittsburgh: University of Pittsburgh Press.
Schimank, Uwe (2008): »Ökonomisierung der Hochschulen: eine Makro-MesoMikro-Perspektive«, in: Karl-Siegbert Rehberg (ed.), Die Natur der Cesellschaft. Verhandlungen des 33. Kongresses der DCS in Kassel 2006, Frankfurt/New York: Campus, 622-635.

Schneider, Beat (2007): »Design as Practice, Science and Research«, in: Ralf Michel (ed.), Design Research Now, Basel: Birkhäuser, 207-218.

Schön, Donald (2003[1983]): The Reflective Practitioner. How Professionals Think in Action, 3rd edition, London: Ashgate.

Scott Brown, Denise (1999): »The Hounding of the Snark«, in: Peter Galison/Emily Thompson (eds.), The Architecture of Science, Cambridge, MA: MIT Press, 375-383.

Silberberger, Jan (2021): »Referencing in Architectural Design«, in: Jan Silberberger (ed.), Against and For Method: Revisiting Architectural Design as Research, Zurich: gta Verlag. 